\title{
Intrapathotype Diversity for Aggressiveness and Pathogen Evolution in Cultivar Mixtures
}

\author{
Christian Lannou
}

Laboratoire de Pathologie Végétale, INRA, BP 01, F-78 850 Thiverval Grignon, France. Accepted for publication 13 January 2001.

\begin{abstract}
Lannou, C. 2001. Intrapathotype diversity for aggressiveness and pathogen evolution in cultivar mixtures. Phytopathology 91:500-510.

A model was developed and used to study the consequences of diversity for aggressiveness within pathotypes on pathogen evolution in two-component and four-component cultivar mixtures. It was assumed that, within a pathotype, a proportion of the isolates would have higher or lower spore efficacy than the average on a given host genetic background. Two situations were examined in which the pathogen can have either independent or negatively correlated values for spore efficacy on different cultivars. In the latter case, a pathogen genotype more aggressive than the average on a host genotype was always less aggressive on

other host genotypes. In the simulations, isolates with greater aggressiveness relative to a host genotype were selected for and increased in frequency. However, because simple pathotypes always reproduced on the same host genotype whereas complex pathotypes were able to grow on several hosts, selection was faster for simple pathotypes. Pathotypes with two different levels of diversity for aggressiveness were compared with nondiversified pathotypes. In order to make comparisons, the effect of a 5 and $10 \%$ cost of virulence on the development of complex pathotypes was simulated. In general, increased diversity within pathotypes reduced the rate of increase of complex pathotypes in host mixtures, and this effect was stronger with greater frequencies of autodeposition of pathogen spores.
\end{abstract}

Many studies have shown that using host mixtures $(3,5,13)$ is an effective disease control method, particularly for airborne pathogens of cereals $(30,34,39)$. In a mixture of cultivars with different resistance genes, pathogens are restricted to susceptible hosts and spore losses on resistant plants result in considerable reductions in disease severity. Because pathogens can rapidly develop new virulences or new virulence combinations, it has been suggested that the large scale use of mixtures might select complex pathotypes that are able to develop on most or all of the mixture components. This would lead to impairment of the mixture efficacy and a more complex pathogen population in terms of virulence combinations. Some experimental studies $(7,8,12,19)$ have addressed this question but it remains difficult to make generalizations on the basis of their conclusions which are partly contradictory. Several authors have developed mathematical models of the response of pathogen populations to host mixtures $(1,2,11$, 24,27,32). All these models include Van der Planck's (36) concept of stabilizing selection, based on the hypothesis that unnecessary genes for virulence will reduce pathogen fitness when infecting a susceptible host. They describe the competition between simple pathotypes, which have greater specificity on one of the host genotypes but are unable to develop on other hosts, and complex pathotypes, which are able to develop on several host genotypes but have a fitness disadvantage related to the number of virulences they carry. Several authors have attempted to measure the effect of unnecessary virulences on pathogen fitness. Measured values of this cost, given as fitness reductions, vary between 14 and 39\% for Puccinia graminis f. sp. avenae (23), 12 and 30\% for Bipolaris maydis (25), 4 and 5.2\% for Puccinia graminis f. sp. tritici (10), and 5.4 and $6.1 \%$ for Erysiphe graminis f. sp. hordei (10). However, in other studies, no relationship was found between pathogen

Corresponding author: C. Lannou; E-mail address: lannou@grignon.inra.fr

Publication no. P-2001-0312-01R

(C) 2001 The American Phytopathological Society fitness and the number of virulences carried, for instance with Puccinia recondita f. sp. tritici (18) or E. graminis f. sp. tritici (4). Martens (28) points out that Puccinia graminis f. sp. avenae pathotypes carrying unnecessary genes for virulence have been present at a large scale and for long periods of time in Canada.

Besides the cost of virulence, other selective effects probably influence pathogen evolution in host mixtures and might reduce the rate at which complex pathotypes develop. For instance, Dileone and Mundt (8) suggest that, for Puccinia striiformis in wheat mixtures, the frequency of complex pathotypes also depends on the genetic background of the pathogen, host composition, and interactions between pathotypes such as induced resistance. A selective effect other than the cost of virulence that might influence simple versus complex pathotype competition in host mixtures is the differential selection of isolates by the host genotype (22). In host mixtures, simple pathotypes always reproduce on the same host genotype, which could result in selection for more aggressive isolates and, as a consequence, in an increase of simple pathotype fitness. Such an effect was first suggested by Leonard (23). He maintained a genetically heterogeneous population of Puccinia graminis f. sp. avenae on two different host genotypes for seven asexual generations and showed that the mean spore efficacy of the population increased by approximately 10 to $15 \%$ on the host on which it had been grown but not on the other one. In another paper, Leonard (24) suggested using mixtures composed of hosts with different genetic backgrounds so the fitness of simple pathotypes would increase by selection of the individuals best adapted to their host genetic background, whereas complex pathotypes should never become well adapted to any of the components. A similar effect was found by Chin and Wolfe (7), for barley powdery mildew in a field situation, where isolates with complex virulence genotypes, sampled from two different cultivars grown in pure stands, had a higher multiplication rate on the cultivars from which they were isolated than on the other one. The differences (Table 6 in literature citation 7) were between 22 and 24\%. This did not occur when the cultivars were grown in mixtures. A similar selective effect was obtained under controlled 
conditions by Gould (9) with a phytophagous mite grown on cucumber or bean. In a recent field study with wheat powdery mildew (37), it was shown that average spore efficacy of complex isolates increased when the pathogen population was grown on a pure stand but did not change in a host mixture. This effect resulted from selection for increased spore efficacy within pure strands, independent of the virulence genes present in the population. Selection for more aggressive pathogen genotypes caused by host genetic background can probably be generalized to many species. Differential interactions between isolates and cultivars that cannot be accounted for by virulence genes have been shown for several fungal pathogens, such as E. graminis f. sp. hordei (29), E. graminis f. sp. tritici (33), Puccinia recondita (20,35), Puccinia striiformis f. sp. tritici (14), Puccinia graminis f. sp. tritici (26), Phytophthora infestans (15), and Puccinia hordei (15).

The present study evaluates the consequences of diversity for aggressiveness within pathotypes in terms of selection within pathotypes as well as for competition between pathotypes. To this end, a mathematical model based on a limited number of parameters but with the ability to simulate a large number of pathogen genotypes was developed.

\section{MATERIALS AND METHODS}

General model. The model simulates the development of successive generations of a pathogen population in a cultivar mixture over a large homogeneous area such as a small-grain crop. It is assumed that cultivars are randomly mixed and their proportion in the mixture does not change over time, that all plants of a cultivar are genetically identical, and that the pathogen reproduces asexually. The pathogen population is composed of different pathotypes, defined by their virulence spectrum on the mixture components, and including different genotypes. A genotype $x$ belonging to pathotype $k$ will be referred to as genotype $k(x)$. The model describes pathogen population development by computing the number of lesions of each pathogen genotype on each host genotype, from one generation to the next. It includes the following parameters (Table 1): $p_{i k(x)}$ indicates the spore production from a single lesion of pathogen genotype $k(x)$ on host genotype $i$. Parameter $p$ represents the number of spores produced during the lesion life. Spore efficacy, $e_{i k(x)}$, or the probability that a spore of genotype $k(x)$ will give a viable lesion when deposited on host genotype $i$. Parameters $e_{i k(x)}$ and $p_{i k(x)}$ define the aggressiveness of genotype $k(x)$ on host $i$. $\varphi$ indicates allodeposition frequency or the probability that a spore from a source plant will be deposited on another plant. The autodeposition frequency is $1-\varphi$. Spores that are lost on the ground or outside the plots are not considered here, and $\varphi$ has the same value for all pathogen and host genotypes. $m_{i}$ indicates the frequency of cultivar $i$ in the host mixture and is unchanged during the epidemic season. $L_{i k(x)}(g)$ indicates the number of lesions of pathogen genotype $k(x)$ on host genotype $i$ for pathogen generation $g$.

The relationship between the number of lesions of pathogen genotype $k(x)$ on host genotype $i$ from one generation to the next can be calculated by considering the lesions issued from allodeposition (equation i) and autodeposition (equation ii) separately. The number of spores produced at generation $g$ on host $j$ that will potentially allo-infect is $\varphi p_{j k(x)} L_{j k(x)}(g)$. The probability of one of these spores being deposited on host $i$ and producing an infection is given by the frequency of host $i$ in the mixture, $m_{i}$, and the spore efficacy, $e_{i k(x)}$. The number of new lesions on cultivar $i$ resulting from allodeposition is then

$$
m_{i} e_{i k(x)} \sum_{j} \varphi p_{j k(x)} L_{j k(x)}(g)
$$

Allo-infecting spores deposited on plants of genotype $i$ originate from all host genotypes in the mixture, including other plants of the same genotype. The source plant itself should be discarded from this calculation but, because the total number of plants is assumed to be large, this correction is negligible. Autoinfecting spores on host $i$ represent a proportion $(1-\varphi)$ of the spores that were produced on the same host by the previous generation. New lesions on cultivar $i$ from autodeposition are then

$$
e_{i k(x)}(1-\varphi) p_{i k(x)} L_{i k(x)}(g)
$$

and by summing and arranging (equations $\mathrm{i}$ and ii), we get equation 1

$$
L_{i k(x)}(g+1)=\varphi m_{i} e_{i k(x)} \sum_{j} p_{j k(x)} L_{j k(x)}(g)+(1-\varphi) e_{i k(x)} p_{i k(x)} L_{i k(x)}(g)
$$

Equation 1 can be generalized for all host genotypes in order to calculate the distribution of pathogen $k(x)$ on the host mixture. We can put this in the form of a matrix equation

$$
L_{k(x)}(g+1)=R \times L_{k(x)}(g)
$$

where $L_{k(x)}$ is a vector representing the distribution of pathogen $k(x)$ on the mixture. Developing the matrices, we get for a mixture with $c$ components and for any pathogen genotype $x$

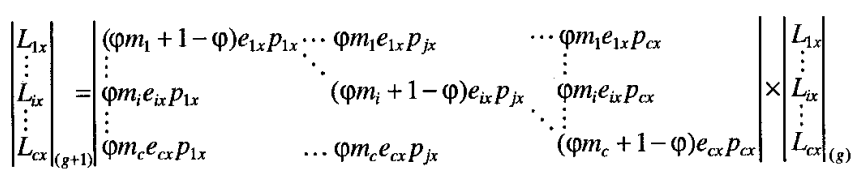

Unfortunately, it is not possible to obtain a simple and general form of matrix $R$ 's eigenvalues, which would give an analytic expression of the pathogen multiplication rate. For this reason, a limited number of situations will be examined, first with no diversity for aggressiveness within pathotypes, then with different levels of diversity.

Model for pathotypes with no diversity for aggressiveness. Assuming that the pathogen is either virulent or avirulent on a given host, with no diversity in aggressiveness, we have $e_{i k}=e$ and $p_{i k}=$ $p$ on a susceptible host, and $e_{i k}=0$ and $p_{i k}=0$ on a resistant host. Then let $\alpha$ be the multiplication factor of the pathogen on a sus-

\begin{tabular}{|c|c|}
\hline Symbol & Definition \\
\hline$\alpha$ & $\begin{array}{l}\text { Multiplication factor of a pathogen on a susceptible host in a } \\
\text { pure stand }(\alpha=\mathrm{ep})\end{array}$ \\
\hline$c$ & Number of host components in the mixture \\
\hline$e_{i k(x)}$ & $\begin{array}{l}\text { Spore efficacy: probability that a spore of genotype } k(x) \text { will } \\
\text { give a lesion when deposited on host genotype } i\end{array}$ \\
\hline$f$ & Fitness of a pathotype, defined as $f_{v}=r_{v} / r_{1}$ \\
\hline$g$ & Index for pathogen generation \\
\hline$\varphi$ & $\begin{array}{l}\text { Allodeposition frequency: probability that a spore from a source } \\
\text { plant will be deposited on another plant }\end{array}$ \\
\hline$k(x)$ & Index for a pathogen genotype $x$ belonging to pathotype $k$ \\
\hline$L_{i k(x)}$ & Number of lesions of pathogen genotype $k(x)$ on host genotype $i$ \\
\hline$L T_{k(x)}$ & Total number of lesions for a pathogen genotype \\
\hline$m_{i}$ & Frequency of cultivar $i$ in the host mixture \\
\hline$p_{i k(x)}$ & $\begin{array}{l}\text { Number of spores produced by a lesion of pathogen genotype } \\
k(x) \text { on host genotype } i \text { during the lesion life }\end{array}$ \\
\hline$r$ & $\begin{array}{l}\text { Multiplication factor of a pathotype in the host mixture } \\
\text { (lesion/lesion) }\end{array}$ \\
\hline$s$ & $\begin{array}{l}\text { Fitness reduction associated to virulences that are not necessary } \\
\text { for a pathogen to infect its host }\end{array}$ \\
\hline$v$ & Number of virulences carried by a pathotype \\
\hline$v_{\text {opt }}$ & Optimal number of virulences for a pathotype \\
\hline
\end{tabular}
ceptible host in a pure stand, $\alpha=$ ep. If we only consider equiproportional host mixtures, then $m_{i}=m$ and equation 1 becomes

$$
L_{i k}(g+1)=\varphi m \alpha \sum_{j} L_{j k}(g)+(1-\varphi) \alpha L_{i k}(g)
$$

TABLE 1 . List of symbols 
Summing all the lesions of pathotype $k$ on the different cultivars, we get

$$
\sum_{i} L_{i k}(g+1)=\sum_{i}\left[\varphi m \alpha \sum_{j} L_{j k}(g)\right]+\sum_{i}(1-\varphi) \alpha L_{i k}(g)
$$

We now consider that the number of virulence genes carried by a pathotype $(v)$ is identical to the number of cultivars susceptible to that pathotype in the mixture. This would be the case if complex pathotypes appeared in a simple pathotype population through single-virulence changes. Let $c$ be the total number of components in the mixture $(m=1 / c)$ and $i^{\prime}$ an index for susceptible hosts only, then

$$
\sum_{i^{\prime}} L_{i^{\prime} k}(g+1)=\varphi m \alpha v \sum_{i^{\prime}} L_{i^{\prime} k}(g)+(1-\varphi) \alpha \sum_{i^{\prime}} L_{i^{\prime} k}(g)=\alpha[1-\varphi \cdot(1-v / c)] \sum_{i^{\prime}} L_{i^{\prime} k}(g)
$$

This gives the multiplication factor per generation $\left(r_{v}\right)$ of a pathotype with $v$ virulences:

$$
r_{v}=\alpha[1-\varphi(1-v / c)]
$$

Because $v$ represents the number of susceptible cultivars, equation 3 is only valid for $1 \leq v \leq c$. We can now introduce a fitness reduction associated to virulences that are not necessary for a pathogen to infect its host. This is commonly referred to as cost for unnecessary virulences $(s)$. Assuming that the fitness reduction is additive (11), the multiplication factor on a susceptible cultivar will be $\alpha$ for a pathotype with a single virulence and $\alpha[1-(v-1) s]$ for a pathotype with $v$ virulences. Taking into account the virulence costs, the multiplication factor of a pathotype with $v$ virulences becomes

$$
r_{v}=\alpha[1-(v-1) s] \times[1-\varphi(1-v / c)]
$$

with the condition that $r_{v}=0$ when $s \leq 1 /(v-1)$, in order to avoid negative values for $r_{v}$. The fitness of this pathotype can be defined in comparison to a single-virulence pathotype $(2,11), f_{v}=r_{v} / r_{1}$, which gives

$$
f_{v}=[1-(v-1) s] \times \frac{1-\varphi(1-v / c)}{1-\varphi(1-1 / c)}
$$

By differentiating $f$ with respect to $v$ we obtain the optimal number of virulences $\left(v_{\mathrm{opt}}\right)$ for the pathogen: $\partial f_{v} / \partial v=0$ for $v_{\mathrm{opt}}$, which gives

$$
v_{\mathrm{opt}}=[(1+s) / 2 s]-c[(1-\varphi) / 2 \varphi]
$$

Equations 5 and 6 are a more general form of Groth's additive model (11), including the effect of autodeposition. Here, the pathogen fitness and optimal number of virulences depend on the cost of a virulence but also on the allodeposition frequency and number of components in the mixture.

Simulation of pathotypes with no diversity for aggressiveness. Equations 5 and 6 were used to calculate the pathogen fitness and optimal number of virulences in a four-component mixture and in a 10-component mixture (Fig. 1), assuming that resistance was complete and mixtures were equiproportional. A cost of virulence $s=0.1$ was used in all the calculations. The allodeposition frequency, $\varphi$, varied between 0.2 and 1.0.

Model for intrapathotype diversity for aggressiveness. Equation 2 can be used to examine a more complex situation, in which the host-pathogen relationship is not only defined in terms of virulence, but also includes diversity for aggressiveness. Several simplifying assumptions are made hereafter: the multiplication parameter $e$ (spore efficacy) determines the compatibility of a pathogen genotype with a host genotype (a compatible interaction
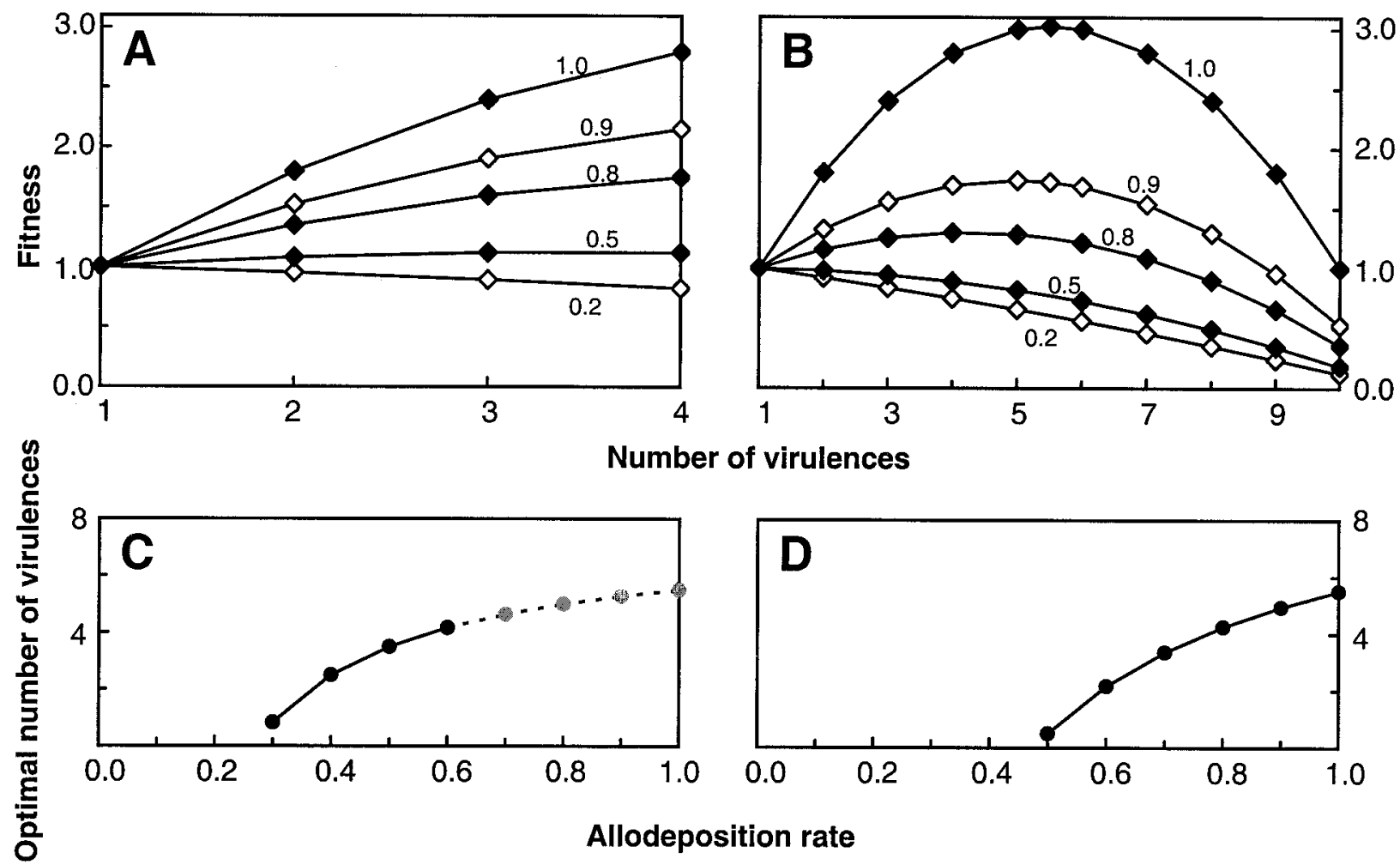

Number of virulences
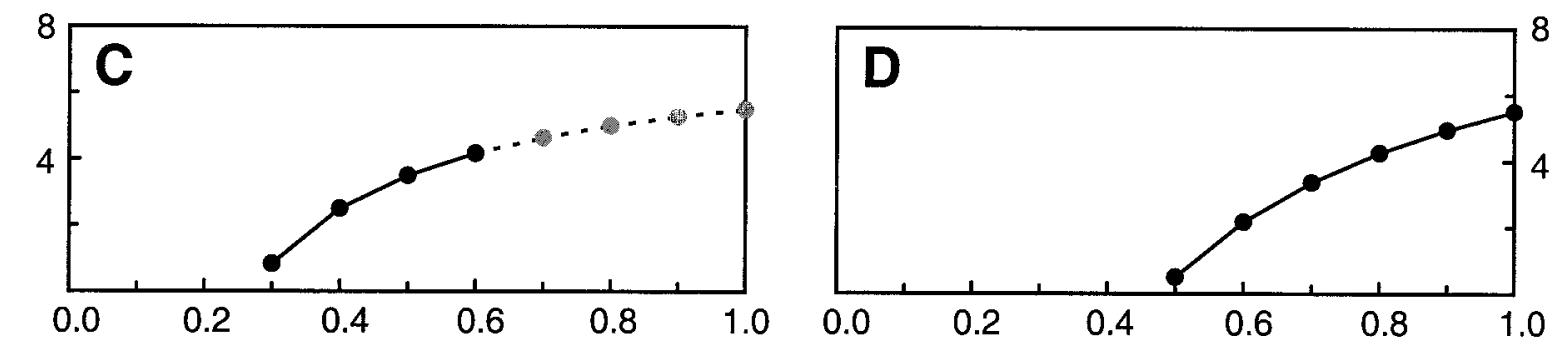

Allodeposition rate

Fig. 1. Relative fitness of a pathogen genotype in $\mathbf{A}$, a four-component mixture or $\mathbf{B}$, a 10-component mixture calculated from equation 5 as a function of the number of virulences it carries and for different values of the allodeposition frequency $(\varphi)$. Values of $\varphi$ are indicated on the curves. Black symbols represent the values of $\varphi$ that were also used in the simulations with diversified pathotypes. Optimal number of virulences for a pathogen genotype in $\mathbf{C}$, a four-component mixture or $\mathbf{D}$, a 10-component mixture, calculated from equation 6 as a function of the allodeposition frequency, $\varphi$. C, Virulence numbers lower than 1 and greater than 4 and $\mathbf{D}$, lower than 1 are outside the range of validity $(1 \leq v \leq c)$ of equations 3 to 6 . A cost of virulence of $s=0.1$ was used in all calculations. 
occurs when $e \neq 0$ ) as well as the aggressivity level of the pathogen; the mixture components are all in the same proportion, i.e., $m_{i}=1 / c$; the spore production parameter is considered to be constant for all genotypes.

Under these assumptions, a few general conclusions can be drawn directly from the model. Equation 1 can be rewritten as

$$
L_{i k(x)}(g+1)=\varphi(1 / c) e_{i k(x)} p \sum_{j} L_{j k(x)}(g)+(1-\varphi) e_{i k(x)} p L_{i k(x)}(g)
$$

For a simple genotype with only one virulence, the total number of lesions $(L T)$ over all mixture components is

$$
L T_{k(x)}(g+1)=(\varphi / \mathrm{c}+1-\varphi) p e_{i k(x)} L T_{k(x)}(g)
$$

This gives the multiplication factor of the simple pathogen genotypes in the mixture $r_{k(x)}=(\varphi / c+1-\varphi) p e_{i k(x)}$ and shows that, within simple pathotypes, relative fitnesses and hence relative genotype frequencies are independent of $\varphi, r_{k(x)} / r_{k(y)}=$ $e_{i k(x)} / e_{i k(y)}$. For simple as well as complex pathotypes, equation 7 becomes

$$
L_{i k(x)}(g+1)=p / c e_{i k(x)} \sum_{j} L_{j k(x)}(g)
$$

when $\varphi=1$, and the total number of lesions of genotype $k(x)$ is

$$
L T_{k(x)}(g+1)=\sum_{i} L_{j k(x)}(g+1)=\left(p / c \sum_{i} e_{i k(x)}\right) L T_{k(x)}(g)
$$

which gives the multiplication factor of any genotype $k(x)$ when $\varphi=1$. Equations 8 and 9 will be used later to explain some of the simulation results.

Simulation of intrapathotype diversity for aggressiveness. The model was used to calculate the frequencies and multiplication factors of genotypes in a pathogen population developing on a two-component or four-component mixture. The number of lesions for each pathogen genotype was computed numerically, each generation using equation 2 . Spore production per lesion was set at $p=8$ (nonviable spores and spores lost on the ground or outside the plot were not considered in the calculations) and, in the initial pathogen population, the mean spore efficacy for any pathotype relative to a given host was set at $\bar{e}=0.5$, which gave a mean multiplication factor of four daughter lesions per lesion on a susceptible host. Diversity for aggressiveness was introduced with a variation in spore efficacy among the different genotypes within each pathotype. Within pathotype $k$, the spore efficacy of the different genotypes relative to host $i, e_{i k(x)}$, ranged into nine classes centered around 0.1 to 0.9 , with a Gaussian frequency distribution, $\mathrm{N}(\bar{e}, \sigma)$ (Fig. 2). Two different initial frequency distributions were used for spore efficacy, with standard deviations of $\sigma=0.6$ and 1.0 (Fig. 2). In all cases, the frequency of complex pathotypes was considered to be $1 / 2,000$ relative to simple pathotypes in initial inoculum.

There are several ways to distribute aggressiveness values relative to two or more host components. If no specific assumption is made, one can consider that the spore efficacy values on the different hosts are independent. In that case, all possible combinations of the spore efficacy values on the different cultivars have to be taken into account. With nine possible values for parameter $e$, the number of possible genotypes would be 81 for a two-virulence pathotype. In order to limit the number of simulated genotypes, however, those with a frequency below $10^{-4}$ were considered to be absent from the population. This reduced the number of genotypes to 45 when $\sigma=1.0$ and to 21 when $\sigma=0.6$, for two-virulence pathotypes. Another possibility was also considered for the distribution of spore efficacy values on different hosts: in the case of unrelated host genotypes, one might assume that if a pathogen genotype is slightly better fitted to one of the host genotypes than the average, it will then be slightly less competitive on the other hosts. Under this hypothesis, a negative relationship was introduced between the spore efficacy values on the different hosts (Table 2). For instance, if $e=0.6$ on the first host, then $e=0.4$ on the others.

In a mixture of two cultivars with two different resistance genes, three different pathotypes can be defined: two simple pathotypes (SR), each virulent on one of the cultivars, and a complex pathotype with both virulences (CR2). However, considering identical frequencies for the mixture components, and because no interaction was defined between pathogen genotypes, all genotypes with the same number of virulences and the same spore efficacy would develop at the same rate. Therefore, the pathogen population could be reduced to one SR and one complex pathotype with two virulence genes (CR2). Pathotype CR2 was simulated either with independent values for spore efficacy or with negatively related values (Table 2 ).

In the four-component mixture, 15 different pathotypes could be defined. For the same reasons as in the two-component mixture, however, the population could be reduced to pathotype SR, one complex pathotype with two virulence genes (CR2), and one complex pathotype with three virulence genes (CR3). Simulations with CR4 did not provide any new information and are not presented. Two levels of complexity were considered for the pathogen population. First, the pathogen population included only pathotypes SR and CR2, with the same distributions for spore efficacy as in the two-component mixture. Second, pathotype CR3 was added to the population under the hypothesis that genotypes with a higher specificity for one of the hosts would have a lower spore efficacy on the two others. Independent values for spore efficacy would have resulted in too many genotypes for CR3, and thus, this situation was not included in the study. The initial structure of pathotype CR3 is given in Table 2.

To allow comparison with other models $(1,11,32)$, nondiversified pathotypes (with a single genotype) were also included in the populations, with an additive fitness reduction $(s)$ of 0,5 , or $10 \%$

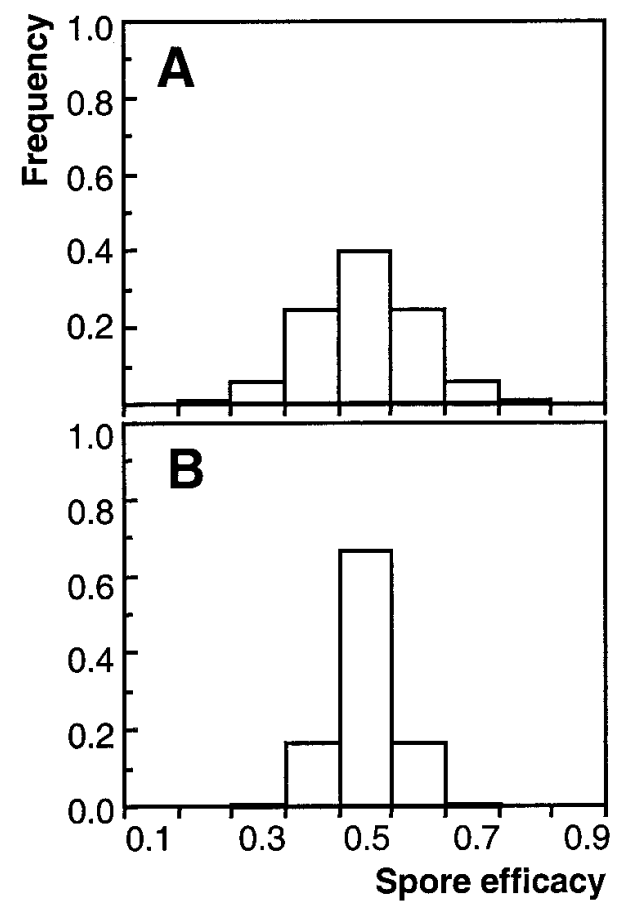

Fig. 2. Frequency distribution of the spore efficacy values, relative to a susceptible host, in initial inoculum. Two Gaussian distributions $(\mathbf{A}, \sigma=1.0$ and $\mathbf{B}, \sigma=0.6$ ) were used in which spore efficacy ranged into nine classes centered around 0.1 to 0.9 . All individuals within the same class were considered to be of the same genotype. These values were used to calculate the genotype frequencies in initial inoculum for the different pathotypes. 
per unnecessary virulence. No fitness reduction was applied to diversified pathotypes. The combined effect of cost of virulence and diversity for aggressiveness was not simulated.

\section{RESULTS}

Pathotypes with no diversity for aggressiveness. Fitness and optimal number of virulences were calculated from equations 5 and 6 (Fig. 1). For nondiversified pathotypes, and when $\varphi=1$, the figures were the same as in Groth's model (11). When the allodeposition rate was reduced, the range of variation in pathogen fitness became smaller and the optimal number of virulences $\left(v_{\mathrm{opt}}\right)$ decreased. This means that a higher autodeposition resulted in a higher multiplication rate of the simpler pathogen genotypes, relative to those with a larger number of virulences. Moreover, there was interaction between the allodeposition frequency and the number of components: when the number of components in the host mixture was increased, changes in the allodeposition rate had greater effects. For instance, according to equation 3, the multiplication factor of a single-virulence pathogen increased by $30 \%$ in a four-component mixture and by $90 \%$ in a 10 -component mixture, when $\varphi$ decreased from 1 to 0.9 .

Effect of intrapathotype diversity for aggressiveness. Figure 2 indicates the distribution of the spore efficacy values for a pathogen genotype in initial inoculum, for two levels of diversity $(\sigma=1.0$ and 0.6$)$. Figure 3 shows the increase in frequency for the two-virulence pathotype CR2 over 30 pathogen generations. Data are given for three values of the allodeposition frequency $\varphi=1$, 0.8 , and 0.5 . In each case, the complex pathotype increased in frequency but its rate of increase was reduced when pathotypes were diversified for aggressiveness. When values of spore efficacy on both cultivars were negatively correlated, the increase in complex pathotype frequency was much slower than for independent values. When intrapathotype diversity was reduced $(\sigma=$ 0.6 ), the complex pathotype increased faster in frequency but the effect of selection for aggressiveness still remained strong in the case of negatively correlated values for spore efficacy (Fig. 3).

Table 2 provides the multiplication factors of the different pathogen genotypes in the cultivar mixture, and Figures 4 and 5 show the frequencies of these genotypes within each pathotype subpopulation, every five generations. From the genotype frequencies and multiplication factors it is possible to calculate the mean multiplication factor of each pathotype in the mixture (Table 3). These figures indicate how the pathogen population evolved in terms of genotypes and pathotypes, during the first 30 generations. Within each pathotype, genotypes with a higher multiplication factor tended to replace the genotypes with the worst fitness (Figs. 4 and 5). This was faster, however, for simple pathotypes and, as a consequence, the mean multiplication rate in the mixture increased faster for simple pathotypes than for complex pathotype CR2 (Table 3). In a few cases, after a large enough number of generations, the multiplication rate of simple pathotypes could exceed that of complex pathotypes, at least temporarily. This happened for instance in the two-component mixture, for $\varphi=0.5, \sigma=1.0$, and correlated values for spore efficacy. In that situation, Figure $3 \mathrm{C}$ shows a slight increase then a decrease of CR2 frequency.

The changes in genotype frequencies for the simple pathotypes did not depend on allodeposition, as shown by equation 8: decreasing $\varphi$ increased the multiplication rates of the simple pathotype genotypes (Table 2) but did not change their relative values.

TABLE 2. Multiplication factors per generation of pathogen genotypes in the two-component mixture and four-component mixture, for different values of the allodeposition frequency, $\varphi^{\mathrm{a}}$

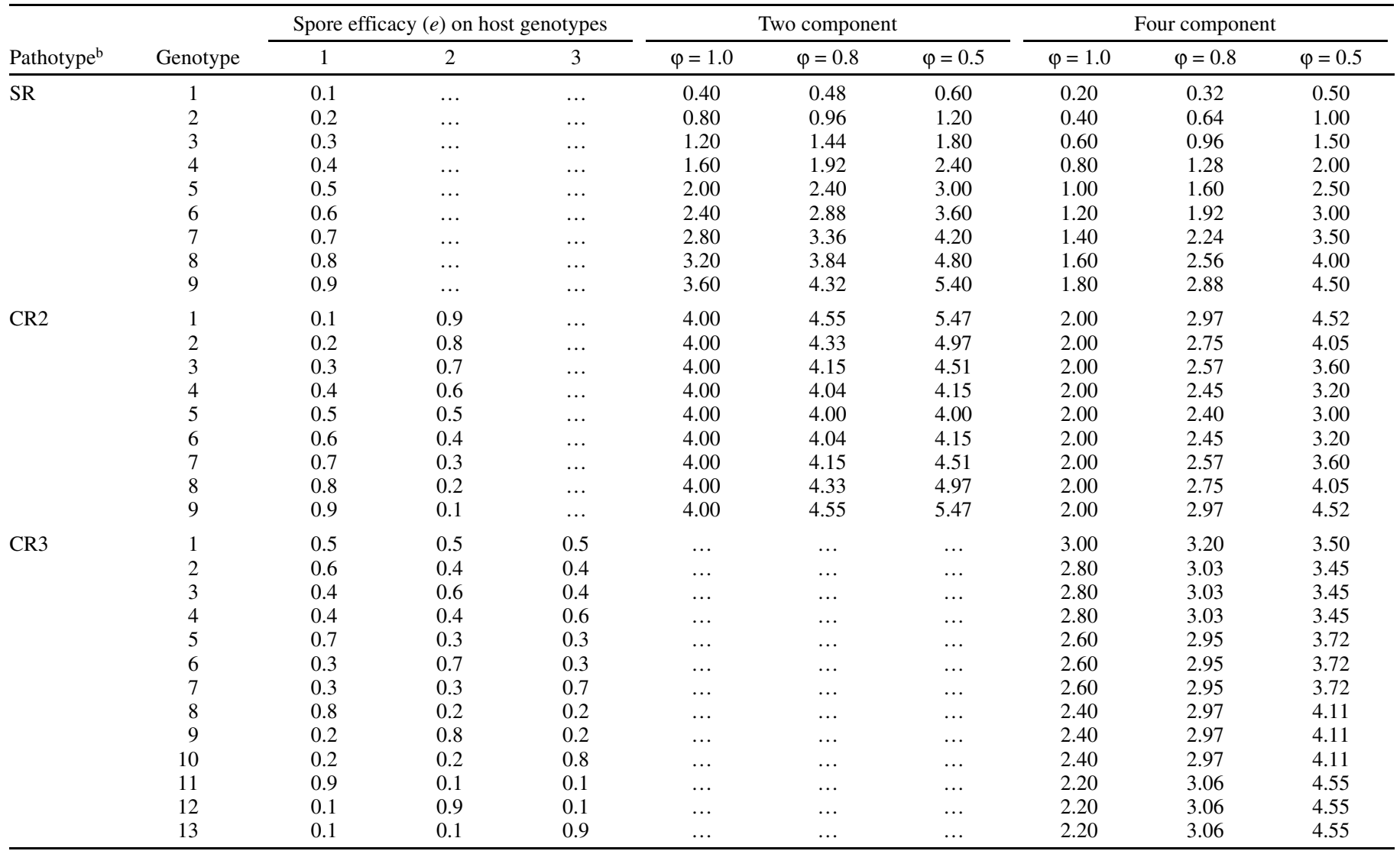

${ }^{a}$ These values were reached after 5 to 10 generations and remained constant afterwards. Values for spore efficacy are indicated for each genotype. It is considered here that pathogen genotypes better fitted than the average on a host genotype are less fitted on the other host genotypes. Data are not shown for genotypes with independent values for spore efficacy on the susceptible hosts.

b SR, simple pathotype; CR2, complex pathotype with two virulence genes; and CR3, complex pathotype with three virulence genes. 
For the complex pathotype CR2, in the case of a negative correlation of the values for spore efficacy on the two cultivars and for $\varphi=1$, all genotypes had the same multiplication rate, as shown by equation 9, and their relative frequencies were constant over the generations. In all other cases, genotypes with a higher specificity for one of the hosts had a higher multiplication rate in the cultivar mixture and were selected from among the CR2 genotypes. Decreasing $\varphi$ made this selection stronger (Figs. 4 and 5).

Changes in frequency for CR2 genotypes can be interpreted in the same way in the two-component and four-component mixture. When $\varphi=1$, the progression of pathotype CR2 was identical in the two-component mixture and the four-component mixture (Fig. 3A) because, even though its multiplication factor was halved in the four-component mixture, it kept the same relative value compared with the simple pathotype (Table 3 ). When $\varphi=0.8$, selection for aggressiveness had a greater effect on the complex pathotype CR2 in the four-component mixture than in the twocomponent mixture. When $\varphi=0.5$, the increase in CR2 was very slow in the four-component mixture, with a final frequency of 0.19 in the case of nondiversified pathotypes and no cost for virulence, and a final frequency of 0.04 for diversified pathotypes, with independent values for $e$ and $\sigma=0.6$.

When a more complex pathotype, CR3, was introduced into the pathogen population, it increased rapidly in frequency relative to
SR and CR2 (Fig. 6). The effect of intrapathotype diversity was greatly reduced when $\varphi=1$, but remained fairly strong for $\varphi=0.8$ and 0.5 . Note that only the hypothesis of negatively correlated values for spore efficacy on the susceptible hosts was considered here. The relative frequencies of CR2 genotypes were the same whether CR3 was introduced into the pathogen population or not, but in the latter case the frequency of pathotype CR2, as a whole, remained very low compared to CR3. When $\varphi=1$, the multiplication rate on the mixture decreased for CR3 genotypes with a higher specificity for one of the mixture components, because of a lower average spore efficacy on the three susceptible cultivars (Table 2). This tendency was reversed when $\varphi$ decreased and genotypes with a higher specificity increased progressively in frequency, as for CR2.

\section{DISCUSSION}

Validity of the model. Spore dispersal in the model is only accounted for by the allodeposition frequency, $\varphi$. Other aspects concerning pathogen development in space may have an effect on pathotype competition. Lannou and Mundt (22) have shown that the spore dispersal gradient and the initial inoculum distribution influence simple pathotype-complex pathotype competition by changing the host mixture efficacy in controlling simple patho-

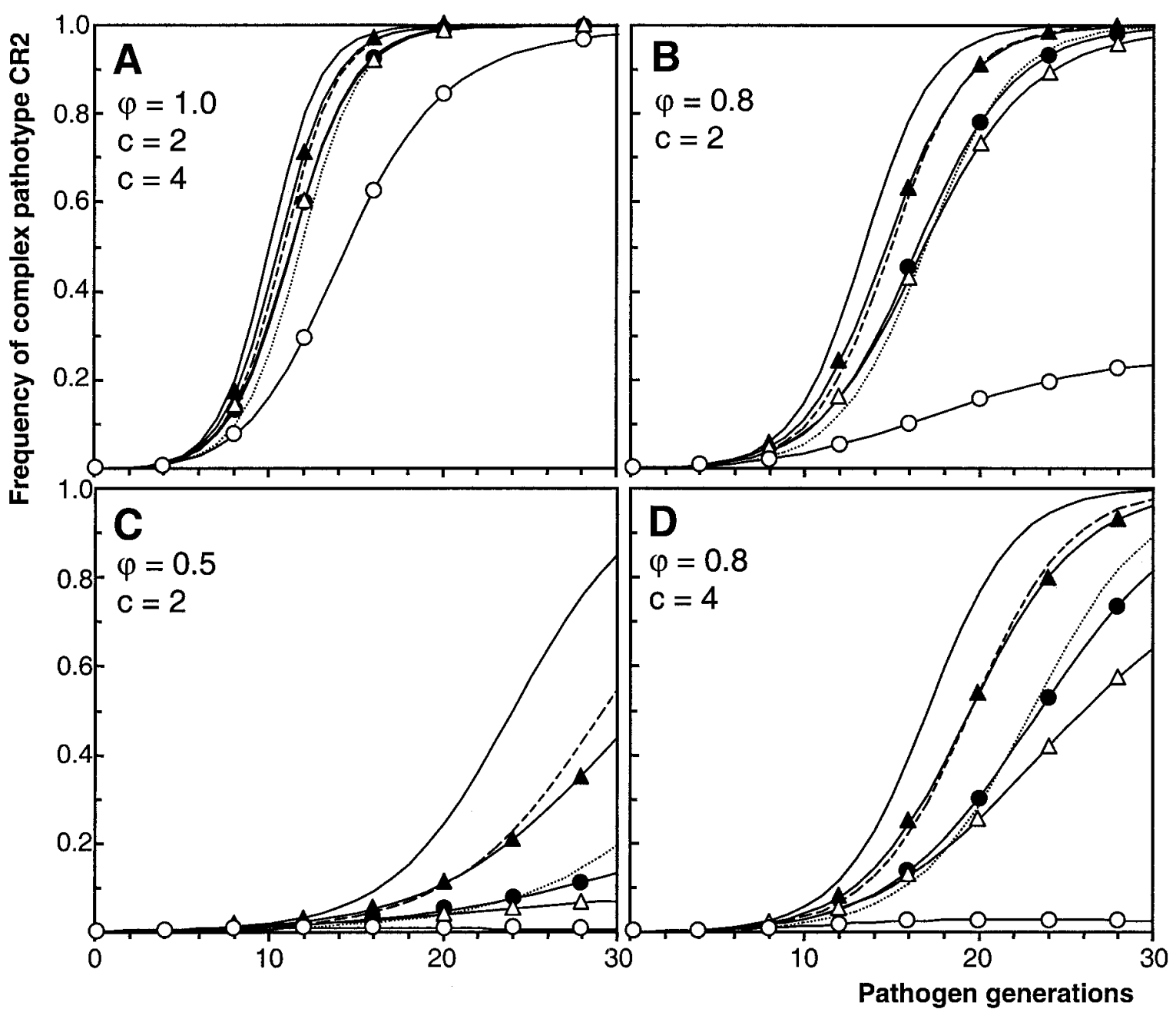

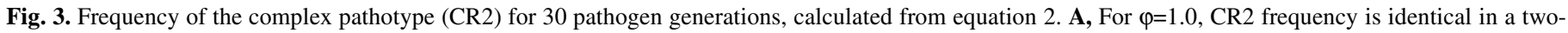

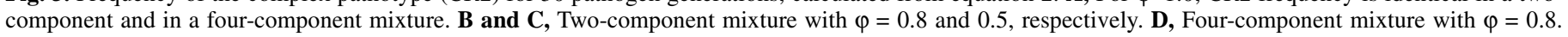

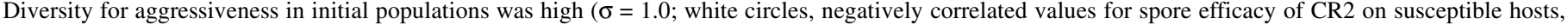

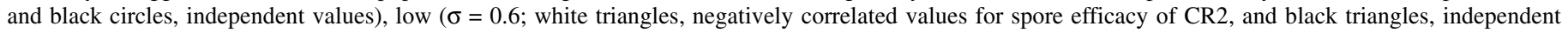

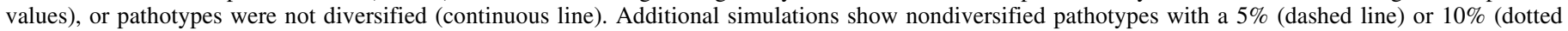
line) cost of virulence. 
types. The same authors also suggest that the relative distribution of the different genotypes in space may alter the emergence rate of a new pathotype. In the model presented here, spatial aspects were reduced to the most significant parameter, $\varphi$, in order to limit model complexity. This choice was based on the fact that, in other papers $(21,31)$, it has been demonstrated that most of the effects of dispersal parameters in host mixtures are accounted for by the allodeposition frequency.

The model describes the genetic structure of the pathogen population, generation after generation. For most polycyclic pathogens, however, several generations are present at the same time in the same plot. From the model, one can predict the structure of each generation individually but not the proportions of the different generations present at the same time on the plot. Nevertheless, if we consider the progressive replacement of old generations by new ones, even with several of them overlapping, and given the regularity of the pathotype frequency changes in the simulations, the model's outputs can be generalized to the total pathogen population.

Another discrepancy between the model and reality is that it does not take into account saturation of the host by the disease.

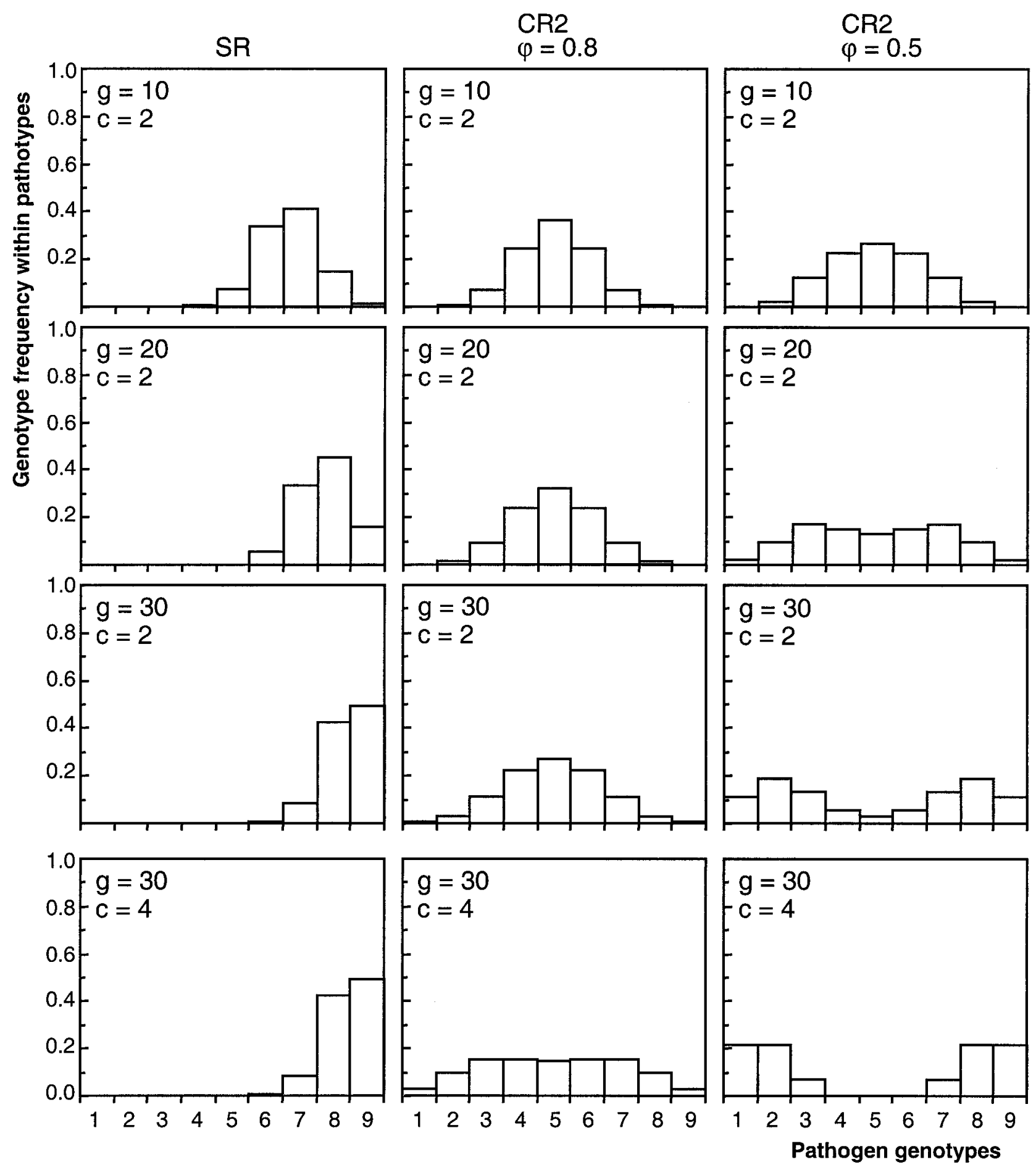

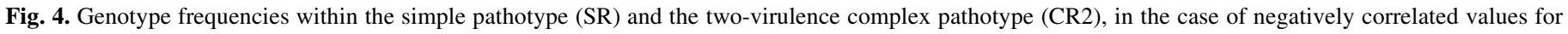
spore efficacy on the mixture components; genotypes with a high spore efficacy on one of the hosts had a low spore efficacy on the other hosts. Initial frequencies $(g=0)$ followed a Gaussian distribution with $\sigma=1.0$ (Fig. 1). Data are shown for generations $(g)$ 10, 20, and 30 in the two-component mixture $(c=2)$ and for generation 30 only in the four-component mixture $(c=4)$. Genotype frequencies were independent of allodeposition frequency $(\varphi)$ for SR. When $\varphi=1.0$, genotype frequencies were constant for CR2 from $g=0$ to 30 and are not shown. 
Data are given here until generation 30 , which is, in most cases, higher than the average number of generations that occur during an epidemic season on an annual crop. It has been shown, however, that density dependence has no major consequences on simple pathotype-complex pathotype competition in host mixtures (21). If we consider that different pathogen genotypes are evenly distributed over the plot, we can assume that saturation has the same effect on all genotypes.

In this study, diversity for aggressiveness is limited to spore efficacy. Although most of the available data on selection for aggressiveness by the host genetic background were obtained for spore efficacy $(7,23,37)$, one can assume that other parameters, for instance spore production rate, would have an effect on pathotype competition in host mixtures.

Autodeposition and pathotype competition. When applied to a system with genetically homogeneous pathotypes, the model can be reduced to a relationship between pathogen fitness, the number of virulences the pathogen carries, the cost of a virulence, the allodeposition frequency, and the number of components in the mixture (equations 4 and 5). Under different forms, this relation-

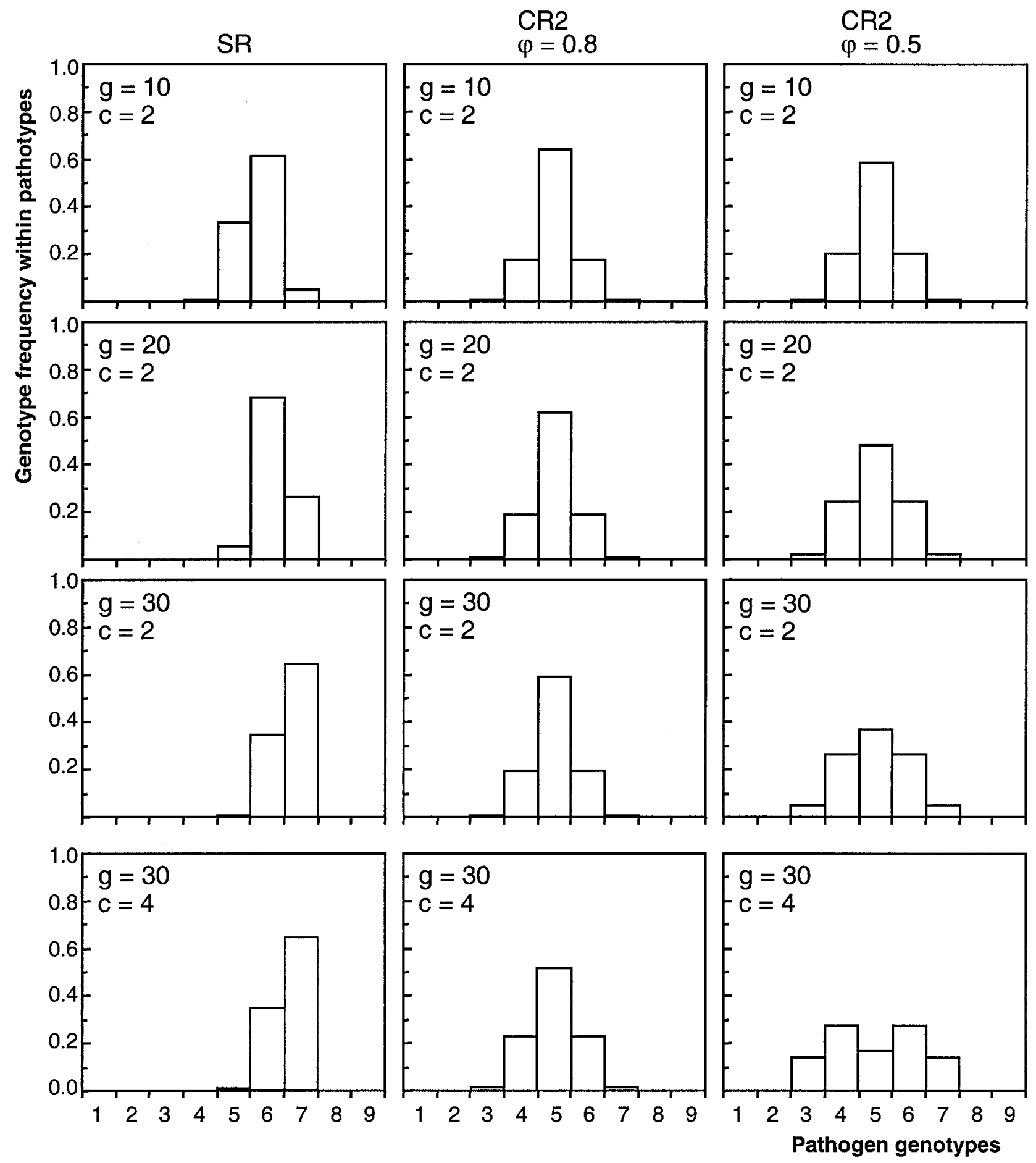

Fig. 5. Genotype frequencies within the simple pathotype (SR) and the two-virulence complex pathotype (CR2), in the case of negatively correlated values for spore efficacy on the mixture components: genotypes with a high spore efficacy on one of the hosts had a low spore efficacy on the other hosts. Initial frequencies $(g=0)$ followed a Gaussian distribution with $\sigma=0.6$ (Fig. 1). Data are shown for generations $(g)$ 10, 20, and 30 in the two-component mixture ( $c=2$ ) and for generation 30 only in the four-component mixture $(c=4)$. Genotype frequencies were independent of allodeposition frequency $(\varphi)$ for SR. When $\varphi=1.0$, genotype frequencies were constant for CR2 from $g=0$ to 30 and are not shown. 
ship has already been explored in other papers $(1,11,24,27,32)$. Particularly, several studies have shown that the allodeposition frequency has major consequences on simple pathotype-complex pathotype competition in cultivar mixtures $(1,21,32)$. In a cultivar mixture, simple pathotypes release spores onto resistant plants for each generation, which results in a disease reduction effect. However, only those spores that are allo-infecting are actually released on the mixture. Therefore, when autodeposition is greater, a larger amount of spores remains on susceptible plants and simple pathotypes multiply better. This does not affect complex pathotypes, or to a lesser extent, depending on the proportion of host components

TABLE 3. Mean multiplication factors per generation of the simple pathotypes (SR) and complex pathotypes (CR2 and CR3) in the twocomponent and four-component mixtures, for different values of the allodeposition frequency $(\varphi)$, two different initial frequency distributions of the genotypes $\left(\sigma=0.6\right.$ and 1.0), and at different pathogen generations ${ }^{\mathrm{a}}$

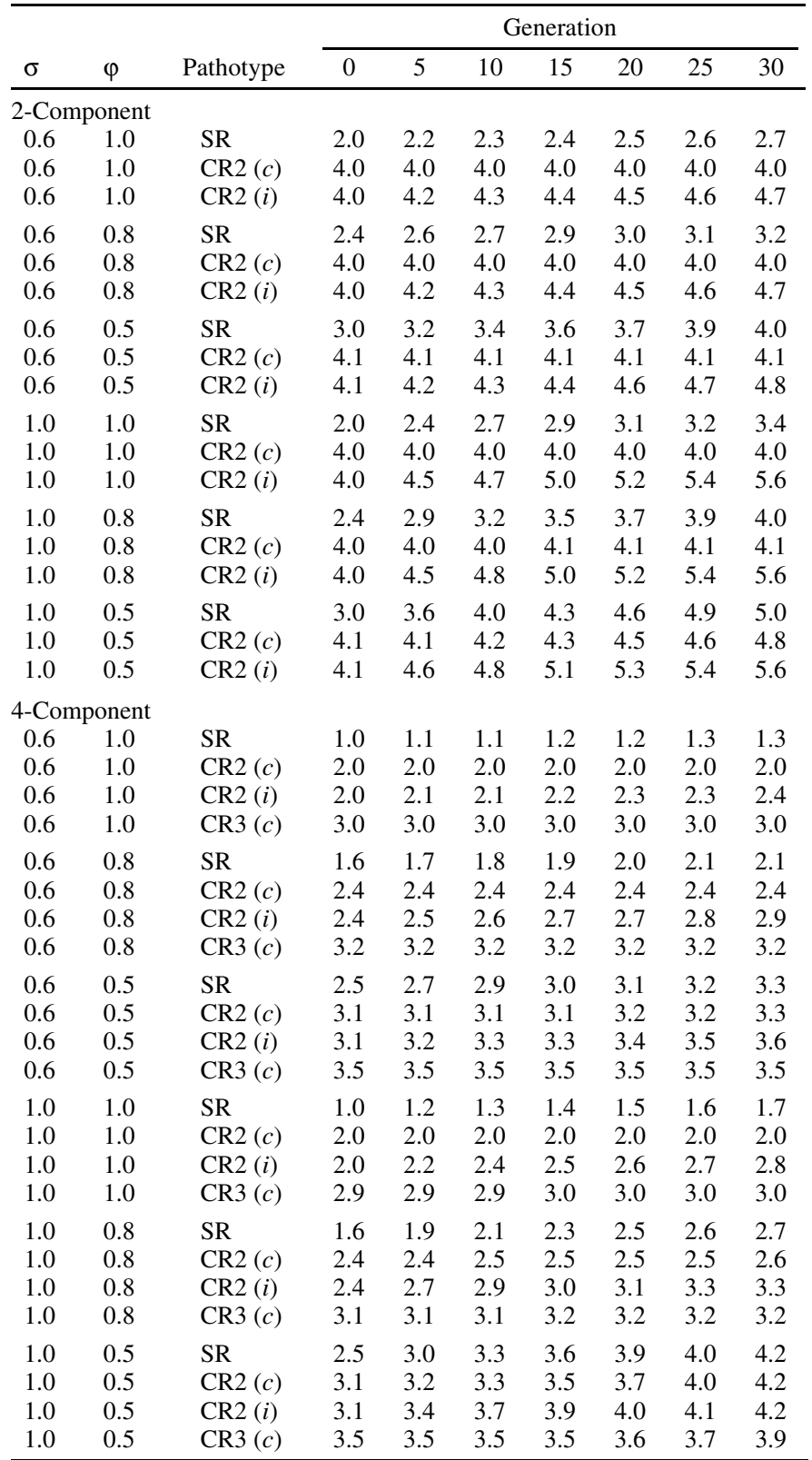

${ }^{\mathrm{a}}$ The figures are calculated from the frequencies within each pathotype and the multiplication factors in the host mixture of the pathogen genotypes. Two hypothesis were considered for the distribution of the spore efficacy values on the different cultivars for the two-virulence pathotype CR2: either the values were negatively correlated $(c)$ or independent $(i)$. No simulation was performed with independent values for spore efficacy for pathotype CR3. on which they can multiply. This is expressed by equation 3 , in which the multiplication rate $r_{v}$ of a pathotype with $v$ virulences is related to $\varphi$ and to $v / c$, the proportion of susceptible cultivars in the mixture. According to equation 3, $\varphi$ has a smaller effect on $r_{v}$ for higher values of $v / c$. For instance, in a two-cultivar mixture, the complex pathotype multiplication rate is expected to be independent of the allodeposition frequency (equation 3 with $v=c$ ). This explains why, when autodeposition is greater, simple pathotypes are expected to be more competitive, relative to complex pathotypes, in host mixtures $(1,21,32)$.

Similar effects were obtained in the simulations with intrapathotype diversity for aggressiveness. Decreasing $\varphi$ increased the multiplication rate of the pathotypes with fewer virulences. For instance, in the four-component mixture at generation 0 , the multiplication rates of pathotypes SR and CR2 were, respectively, 38.1 and $69.1 \%$ of that of CR3, when $\varphi=1$. These numbers rose to 56.6 and $78.0 \%$ when $\varphi$ was set at 0.8 , and 78.8 and $89.1 \%$ when $\varphi$ was set at 0.5 . The effect of $\varphi$ on pathotype competition can be seen in Figures 3 and 6 for all the situations simulated; complex pathotype progression was slower when autodeposition was greater.

Number of host genotypes and pathotype competition. When the number of components in the mixtures was increased, the proportion of plants that were resistant to a given pathotype became greater. Then, the proportion of the pathogen multiplication rate, which was accounted for by allodeposition, was lower than that which was accounted for by autodeposition. One consequence was that the relative fitness of complex pathotypes was lower in mixtures with more components. For instance, according to equation 5 and with $\varphi=0.8$, the fitness of a two-virulence pathotype relative to a single-virulence pathotype decreased from 1.67 to 1.50 when the number of components in the mixture was raised from two to four. More generally, the effects of autodeposition on pathotype fitness should be greater in mixtures with more components (equation 3). Interaction between the allodeposition frequency and the number of components is also described by Østergaard (32).

The simulation of diversified pathotypes also demonstrated the same interaction: in the simulations with SR and CR2, the increase in frequency of CR2 was identical in the mixtures with two or four components when $\varphi=1$, whereas it was substantially slower in the four-component mixture when $\varphi=0.8$ (Fig. 3). It seems that the replacement of single-virulence pathotypes by twovirulence pathotypes is slower in a four-component mixture than in a two-component mixture.

Selection for increased aggressiveness by host genotype. In the simulations, there was strong selection among the SR genotypes for those which were more aggressive on the matching susceptible cultivar. As a result, the mean multiplication rate of the simple pathotype progressively increased during the epidemic. This increase was independent of the allodeposition frequency. Decreasing $\varphi$ made the SR genotypes multiply faster but the effect was the same for each genotype and their relative frequencies did not change. For complex pathotype CR2, under the hypothesis of a negative correlation between spore efficacy values on the mixture components and with $\varphi=1$, the pathogen reproduced randomly on both susceptible cultivars and no selection occurred within the pathotype. When $\varphi$ was reduced, autodeposition tended to amplify the pathogen genotypes on the hosts on which they were best fitted (Figs. 4 and 5) and therefore, the genotypes that were more specifically adapted to one of the mixture components increased in frequency, but more slowly for simple pathotypes. In the simulations with independent spore efficacy values, the situation was different because the average spore efficacy on the susceptible hosts varied among pathogen genotypes. Here, even when $\varphi=1$, the genotypes with a higher average spore efficacy tended to replace the others. When $\varphi$ was decreased, this replacement was faster for the same reason as above. 
Because no interaction among genotypes is included in the model, changes in frequency among pathogen genotypes only result from different multiplication factors. Therefore, the genotype with the largest multiplication factor will always dominate in the population in the long term, irrespective of initial frequencies. However, until an equilibrium is reached, the changes in genotype composition and hence the rate at which the complex pathotype increases in the population is largely dependent on the initial structure of the population. In the long term, it seems that mixtures should select specialized genotypes, better adapted to one of the host components. For instance, in Figure 4, for the four-component mixture at generation 30, the complex pathotype is split into two subpopulations of genotypes with a high fitness for one or the other of the susceptible hosts and genotypes with intermediate values for spore efficacy have disappeared. Whether this could have consequences for the long term evolution of pathogens in cultivated areas is difficult to say and probably depends on the number of generations the pathogen is able to produce until the cultivars are replaced.

When no diversity for aggressiveness is introduced in the model, equation 6 allows to predict the optimal number of virulence the pathogen might accumulate, as a function of the cost of virulence. In the absence of an analytic expression for the pathogen multiplication rate for diversified pathotypes, this conclusion remains difficult to generalize. Diversity for aggressiveness clearly reduces the complex pathotype fitness relative to simple pathotypes but its consequences on the competition between complex pathotypes with different virulence factors has not been explored.

Simulations were performed over 30 generations on the same host mixture in order to show, as well as possible, the changes in the pathogen population. Starting from a simple pathotype with a mean spore efficacy value of $e=0.5(\sigma=1.0)$ on the susceptible host, selection for aggressiveness led to a mean value for $e$ of approximately 0.8 . This is probably higher than what could be observed in the field and should be considered as the consequence of selection for aggressiveness in the absence of any other effect. In a real situation, other factors are involved in pathogen fitness, such as climatic conditions $(16,28,38)$. Also, in an epidemic season, most pathogen develop less than 30 generations and considerable changes in the population genetic structure may occur between two successive seasons, which is not accounted for by the model.

The model shows a strong interaction between selection for aggressiveness within pathotypes and the rate of autodeposition. This probably could be used in practical disease management. Increasing the autodeposition frequency, for instance by growing row mixtures (12) instead of random mixtures, and choosing mixture components with different genetic backgrounds should considerably reduce the rate of increase of complex pathotypes.

Genetic diversity within pathotypes. Several genotypes were defined within each pathotype according to their aggressiveness

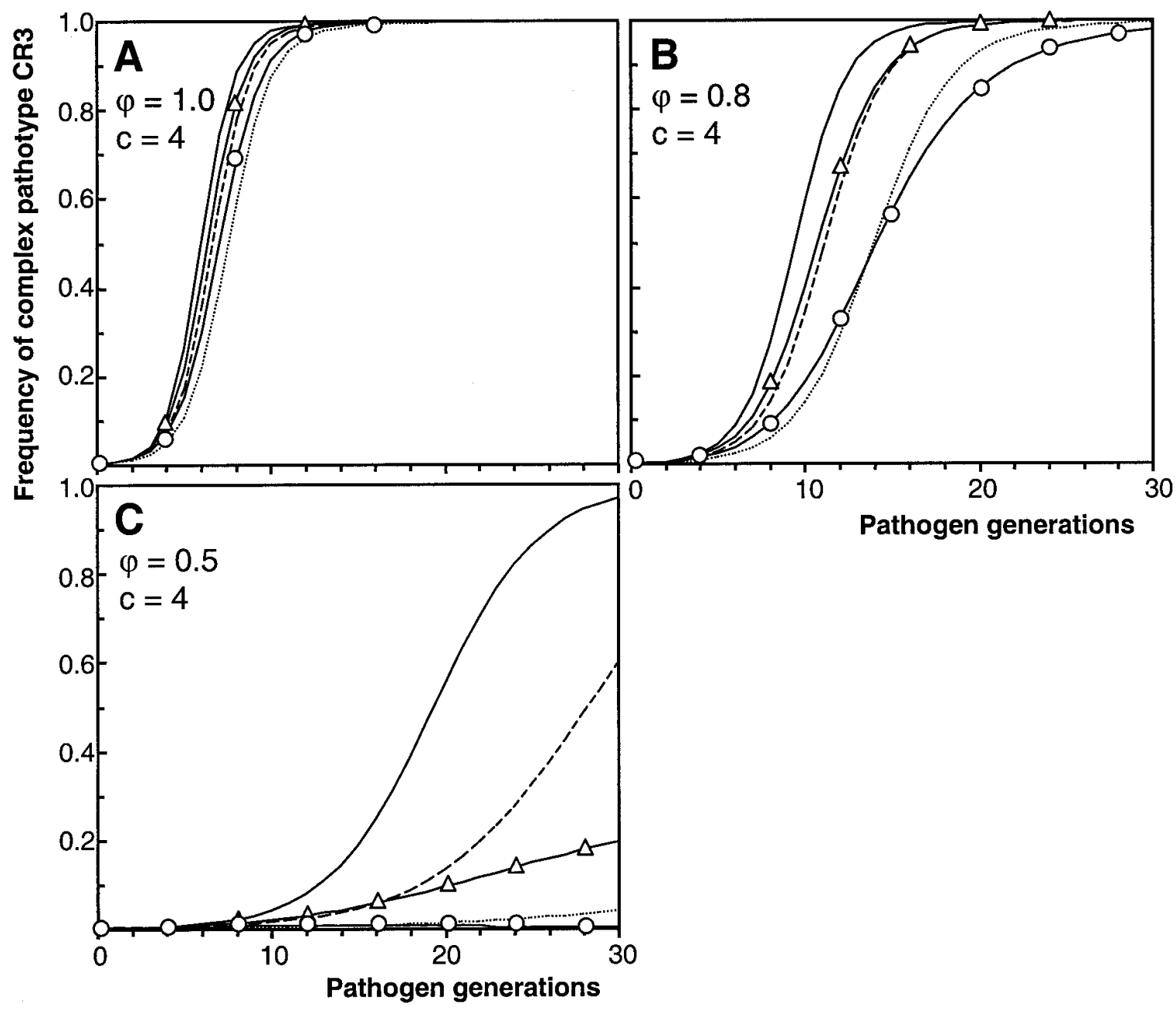

Fig. 6. Frequency of complex pathotype (CR3) in a four-component mixture, for 30 pathogen generations, calculated from equation 2 . A, allodeposition frequency $(\varphi)=1.0 ; \mathbf{B}, \varphi=0.8$; and $\mathbf{C}, \varphi=0.5$. Diversity for aggressiveness in initial populations was high $(\sigma=1.0$, white circles), low $(\sigma=0.6$, white triangles), or pathotypes were not diversified (continuous line). Values for spore efficacy on the mixture components were negatively correlated; genotypes with a high spore efficacy on one of the hosts had a low spore efficacy on the other hosts. Additional simulations show nondiversified pathotypes with a 5\% (dashed line) or $10 \%$ (dotted line) cost per unnecessary virulence. 
level. The underlying hypothesis was that of intrapathotype diversity for aggressiveness on a host genotype. It was assumed that, on a given host genetic background, a few isolates of a pathotype would reproduce better or worse that the average. Although many studies $(6,7,14,15,20,23,26,29,33,35)$ show differential interactions between isolates and cultivars, no reference is available concerning the way aggressiveness varies among isolates of the same pathotype on different cultivars. Particularly, we do not know whether the aggressiveness levels on different cultivars are independent or not. If an isolate is more adapted to a host genetic background, is it necessarily less adapted to other unrelated genotypes? This question probably has strong implications for the magnitude of selection for increased aggressiveness and might change the rate at which simple pathotypes are replaced by complex pathotypes in host mixtures. Also, the range of variation in aggressiveness among isolates belonging to the same pathotype, in a field population, is difficult to estimate. The range of variation used for spore efficacy was from $e=0.1$ to $0.9(\sigma=1.0)$ or from $e=0.3$ to $0.7(\sigma=0.6)$. In other simulations (data not shown) performed with $\sigma=0.4(0.4<e<0.6)$, the effect of selection for aggressiveness appeared negligible.

So far, most studies on selection for complex pathotypes in host mixtures focused on major gene interactions (17). The results presented here, along with experimental studies $(7,23,37)$, suggest that diversity for aggressiveness within pathotypes is a general mechanism that should be taken into account in order to understand the influence of host selection in cultivar mixtures.

\section{LITERATURE CITED}

1. Barrett, J. A. 1980. Pathogen evolution in multilines and variety mixtures. Z. Pflanzenkr. Pflanzenschutz 87:383-396.

2. Barrett, J. A., and Wolfe, M. S. 1978. Multilines and super-races - a reply. Phytopathology 68:1535-1537.

3. Borlaug, N. E. 1953. New approach to the breeding of wheat varieties resistant to Puccinia graminis tritici. (Abstr.) Phytopathology 43:467.

4. Bronson, C. R., and Ellingboe, A. H. 1986. The influence of four unnecessary genes for virulence on the fitness of Erysiphe graminis f. sp. tritici. Phytopathology 76:154-158.

5. Browning, J. A., and Frey, K. J. 1969. Multiline cultivars as a means of disease control. Annu. Rev. Phytopathol. 7:355-382.

6. Caffier, V., Hoffstadt, T., Leconte, M., and De Vallavieille-Pope, C. 1996. Seasonal changes in pathotype diversity in French populations of barley powdery mildew. Plant Pathol. 45:454-468.

7. Chin, K. M., and Wolfe, M. S. 1984. Selection on Erysiphe graminis in pure and mixed stands of barley. Plant Pathol. 33:535-546.

8. Dileone, J. A., and Mundt, C. C. 1994. Effect of wheat cultivar mixtures on populations of Puccinia striiformis races. Plant Pathol. 43:917-930.

9. Gould, F. 1979. Rapid host range evolution in a population of the phytophagous mite Tetranychus urticae Koch. Evolution 33:791-802.

10. Grant, M. W., and Archer, S. A. 1983. Calculation of selection coefficients against unnecessary genes for virulence from field data. Phytopathology 73:547-551.

11. Groth, J. V. 1976. Multilines and "super races": A simple model. Phytopathology 66:937-939.

12. Huang, R., Krank, J., and Welz, H. G. 1994. Selection of pathotypes of Erysiphe graminis f. sp. hordei in pure and mixed stand of spring barley. Plant Pathol. 43:458-470.

13. Jensen, N. F. 1952. Intra-varietal diversification in oat breeding. Agron. J. 44:30-34.

14. Johnson, R., and Taylor, A. J. 1972. Isolates of Puccinia striiformis collected in England from the wheat varieties Maris Beacon and Joss Cambier. Nature 238:105-106.

15. Johnson, R., and Taylor, A. J. 1976. Spore yield of pathogens in investi- gations of the race-specificity of host resistance. Annu. Rev. Phytopathol. 14:97-119.

16. Katsuya, K., and Green, G. J. 1967. Reproductive potentials of races $15 \mathrm{~B}$ and 56 of wheat stem rust. Can. J. Bot. 45:1077-1091.

17. Knogge, W., and Marie, C. 1997. Molecular characterization of fungal avirulence. Pages 329-346 in: The Gene-for-Gene Relationship in PlantParasite Interactions. I. R. Crute, E. B. Holub, and J. J. Burdon, eds. CAB International, Wallingford, U.K.

18. Kolmer, J. A. 1993. Selection in a heterogeneous population of Puccinia recondita f. sp. tritici. Phytopathology 83:909-914.

19. Kolmer, J. A. 1995. Selection of Puccinia recondita f. sp. tritici virulence phenotypes in three multilines of Thatcher wheat lines near isogenic for leaf rust resistance genes. Can. J. Bot. 73:1081-1088.

20. Kuhn, R. C., Ohm, H. W., and Shaner, G. E. 1978. Slow leaf-rusting resistance in wheat against twenty-two isolates of Puccinia recondita. Phytopathology 68:651-656.

21. Lannou, C., and Mundt, C. C. 1996. Evolution of a pathogen population in host mixtures: Simple race - complex race competition. Plant Pathol. 45:440-453.

22. Lannou, C., and Mundt, C. C. 1997. Evolution of a pathogen population in host mixtures: Rate of emergence of complex races. Theor. Appl. Genet. 94:991-999.

23. Leonard, K. J. 1969. Selection in heterogeneous populations of Puccinia graminis f. sp. avenae. Phytopathology 59:1851-1857.

24. Leonard, K. J. 1969. Genetic equilibria in host-pathogen systems. Phytopathology 59:1858-1863.

25. Leonard, K. J. 1977. Virulence, temperature optima, and competitive abilities of isolines of races $\mathrm{T}$ and $\mathrm{O}$ of Bipolaris maydis. Phytopathology 67:1273-1279.

26. Loegering, W. Q. 1951. Survival of races of wheat stem rust in mixtures. Phytopathology 41:56-65.

27. Marshall, D. R. 1989. Modeling the effects of multiline varieties on the population genetics of plant pathogens. Pages 284-317 in: Plant Disease Epidemiology. II. Genetics, Resistance and Management. Vol. 2. K. J. Leonard and W. E. Fry, eds. McGraw-Hill, New York.

28. Martens, J. W. 1973. Competitive ability of oat stem rust races in mixtures. Can. J. Bot. 51:2233-2236.

29. Meah, M. B., Hermansen, J. E., and Jørgensen, J. H. 1982. Interactions between powdery mildew isolates and compatible barley cultivars. Phytopathol. Z. 105:45-50.

30. Mundt, C. C. 1989. Modeling disease increase in host mixtures. Pages 150-181 in: Plant Disease Epidemiology II. Genetics, Resistance and Management. Vol. 2. K. J. Leonard and W. E. Fry, eds. McGraw-Hill, New York.

31. Mundt, C. C., and Leonard, K. J. 1986. Analysis of factors affecting disease increase and spread in mixtures of immune and susceptible plants in computer-simulated epidemics. Phytopathology 76:832-840.

32. Østergaard, H. 1983. Predicting development of epidemics on cultivar mixtures. Phytopathology 73:166-172.

33. Rouse, D. I., Nelson, R. R., Mackenzie, D. R., and Armitage, C. R. 1980. Components of rate-reducing resistance in seedlings of four wheat cultivars and parasitic fitness in six isolates of Erysiphe graminis f. sp. tritici. Phytopathology 70:1097-1100.

34. Smithson, J. B., and Lenné, J. M. 1996. Varietal mixtures: A viable strategy for sustainable productivity in subsistence agriculture. Ann. Appl. Biol. 128:127-158.

35. Todorova, M., and Kurjin, H. 1991. Studies on competitive ability of some physiological races of Puccinia recondita Rob. ex Desm. f. sp. tritici Erikss. Cereal Rusts Powdery Mildews Bull. 19:59-64.

36. Van der Plank, J. E. 1963. Plant Diseases: Epidemics and Control. Academic Press, New York.

37. Villaréal, L. M. M. A., and Lannou, C. 2000. Selection for increased spore efficacy by host genetic background in a wheat powdery mildew population. Phytopathology 90:1300-1306.

38. Weltz, H. G., Nagarajan, S., and Kranz, J. 1990. Short-term virulence dynamics of Erysiphe graminis f. sp. hordei in a single epidemic on two susceptible barley cultivars. Z. Pflanzenkr. Pflanzenschutz 97:250-262.

39. Wolfe, M. S. 1985. The current status and prospects of multiline cultivars and variety mixtures for disease resistance. Annu. Rev. Phytopathol. 23:251-273. 